\title{
Taking Turns or Not? Children's Approach to Limited Resource Problems in Three Different Cultures
}

\author{
Henriette Zeidler and Esther Herrmann \\ Max Planck Institute for Evolutionary Anthropology
}

\author{
Daniel B. M. Haun \\ Max Planck Institute for Evolutionary Anthropology \\ and Leipzig University and Max Planck Institute for \\ Psycholinguistics
}

\author{
Michael Tomasello \\ Max Planck Institute for Evolutionary Anthropology
}

\begin{abstract}
Some problems of resource distribution can be solved on equal terms only by taking turns. We presented such a problem to 168 pairs of 5- to 10-year-old children from one Western and two non-Western societies (German, Samburu, Kikuyu). Almost all German pairs solved the problem by taking turns immediately, resulting in an equal distribution of resources throughout the game. In the other groups, one child usually monopolized the resource in Trial 1 and sometimes let the partner monopolize it in Trial 2, resulting in an equal distribution in only half the dyads. These results suggest that turn-taking is not a natural strategy uniformly across human cultures, but rather that different cultures use it to different degrees and in different contexts.
\end{abstract}

School-age children have a strong bias toward distributing resources equally. For example, in studies with children from Western industrialized populations, Fehr, Bernhard, and Rockenbach (2008) found that children from the age of 7 or 8 years prefer to share a windfall resource between themselves and another child equally, and other researchers found that 8-year-old children will even sacrifice or destroy resources to make sure that there is an equal division (Blake \& McAuliffe, 2011; Shaw \& Olson, 2012). In a large cross-cultural study involving both Western and non-Western children, however, House et al. (2013) found that after about

Esther Herrmann, Daniel B. M. Haun, and Michael Tomasello contributed equally to this article.

We thank the District Education Offices of Laikipia Central and Samburu and the local Kenyan and German schools for supporting our research, Colleen Stephens for statistical advice, and Elena Rossi, Melissa Cherouny, and Monique Horstmann for help with data collection and coding. Many thanks also to our reviewers, whose thoughtful suggestions have been of great help throughout the revision process. And last but definitely not least, special thanks to all the children who participated in our studies and to our Kenyan friends and assistants who made this work possible. Funding for this research was provided by the Max Planck Society and the Jacobs Foundation.

Correspondence concerning this article should be addressed to Henriette Zeidler, Department of Developmental and Comparative Psychology, Max Planck Institute for Evolutionary Anthropology, Deutscher Platz 6, D-04103, Leipzig, Germany. Electronic mail may be sent to zeidler@eva.mpg.de.
8 or 9 years of age differences emerged that were aligned with the social norms of the respective cultures. How children distribute resources thus seems to be influenced - at least by 8 or 9 yearsby their social and cultural environments (e.g., Benenson, Pascoe, \& Radmore, 2007).

An interesting situation arises when children are confronted with a resource that is not spatially divisible, and can be accessed by only one person at a time. A natural solution to the adult Western mind in such situations is for the interested parties to take turns on an equal basis. However, it is possible that this is a solution that has been invented in some cultures by adults, and children learn it as a social norm. There are two experimental paradigms that have been widely used for studying dyadic interactions of children in such contexts. First are studies of children's conflicts with peers over access to a toy. In these studies, typically, one child monopolizes a toy but then yields to another after some time (with or without encouragement; e.g., Hay \& Ross, 1982; Putallaz \& Sheppard, 1990; see also Green \& Rechis, 2006, for

(C) 2016 The Authors

Child Development (C) 2016 Society for Research in Child Development, Inc. All rights reserved. 0009-3920/2016/8703-0005

DOI: $10.1111 /$ cdev. 12505 
a review). This paradigm has also been used cross-culturally and significant differences in how children negotiate access have been found (Sparkes, 1991). But although letting someone else use the toy may in some sense be thought of as turn-taking, it is unclear if the children are aiming for an equal distribution-or else just yielding when either they are forced to or when they have tired of playing with the toy. The second paradigm is represented by a series of studies by Madsen (1971) and others (e.g., Madsen \& Lancy, 1981; Madsen \& Yi, 1975; Shapira, 1976). Here, the paradigm is an apparatus in which either of two children (on opposite sides) can pull in resources for themselves. The trick is that if they both pull at the same time no one gets anything. Across several different cultures children in this situation come to use a turn-taking strategy. But here the turn-taking strategy is almost forced as there is the risk of complete failure for both if they do not work out some cooperative arrangement.

In the current study, therefore, we wanted to assess children's preference for a turn-taking strategy in a situation in which it was clear from the beginning that the resource could be accessed multiple times and that one individual could potentially monopolize it for the entire game. In contrast to previous work, we created a situation in which the pair was able to keep track of the distribution, allowing them to adjust their strategy throughout the game. We tested same-age, same-sex peer dyads of 5- to 10-year-old children in a limited resource problem in which turn-taking would seem to be an obvious strategy for achieving equality. Specifically, children played a fishing game in which they could retrieve rewards with a single hook, such that one child could dominate it totally across time or they could take turns using the hook (either within or across trials). However, since immediate balancing seems more important for individuals who typically engage in ephemeral interactions with anonymous others (Henrich et al., 2010), turn-taking might be a strategy that is unique to large-scale, Western societies. Children growing up in small, non-Western communities surrounded by kin might take a completely different approach.

In addition to our sample from a Western industrialized society (Germany), we thus tested Samburu children from Northern Kenya, who grow up in traditional, extended families in a remote part of the country. To reduce the likelihood of our results being due to a specific aspect of Samburu culture, we also tested children from another, very different Kenyan group, the Kikuyu. Children from both groups came from small, rural communities, in which neighbors are typically family members (see Supporting Information for a description of the ethnographic backgrounds).

We also ran two follow-up studies to determine whether children would judge that taking turns was the "right thing to do" for third parties interacting in similar situations, and whether they would be more likely to take turns if others were watching or subsequently choosing them as partners (and so there were potentially reputational benefits to cooperation).

\section{Study 1 \\ Method}

\section{Participants}

A total of 218 children from Kenya (100 Samburu and $118 \mathrm{Kikuyu}$ ) and 118 children from Germany were included in Study 1. All participants were between 5 and 10 years old. We did not record age to the level of months since this is not reliably known for most children in the two Kenyan communities. To account for the lack of more accurate information, we also used a wider age window for pairing our German dyads, so the age difference between partners varied between 0 and 364 days. Even though we made sure not to pair siblings, it is possible that some of the Kenyan children who played together were as closely related as cousinswhich would have very rarely been the case in our German dyads. In Germany, we tested 60 girls $\left(M_{\text {age }}=7.5\right)$ and 58 boys $\left(M_{\text {age }}=7.0\right)$. Another 2 German 9-year-old boys were tested but excluded because they had not followed the game rules during the test. Among the Kikuyu, 46 girls $\left(M_{\text {age }}=7.0\right)$ and 72 boys $\left(M_{\text {age }}=8.0\right)$ participated in our study, and in Samburu, we tested 48 girls $\left(M_{\mathrm{age}}=7.5\right)$ and 52 boys $\left(M_{\mathrm{age}}=7.5\right)$. Another 4 Samburu girls (2 aged 6, and 2 aged 10 years) were tested but excluded because they had not followed the game rules during the test. German children came from middle-class families in a medium-sized town in the eastern part of the country. Samburu children came from several small homesteads about $1 \mathrm{hr}$ from Wamba, the nearest town, and Kikuyu children lived in small villages near the Kenyan town of Nanyuki. Children who were in the required age range were randomly chosen from the class lists and asked to join the experimenters for a game after school. Participation was fully voluntary, and children were usually eager to play. 


\section{Materials}

The setup consisted of two long plexiglass tubes with small plastic containers inside and a short, empty plexiglass tube (two during training). One long tube was filled with 10 blue containers, and the other one with 10 red containers (see Figure 1). Each of the containers had a small bead inside, which could be used to make a bracelet. In order to obtain the beads, children had to fish the containers from the long tubes and place them in the short one using a hook. The short tube held a maximum of eight containers, thus limiting the number of beads to be obtained in each game. For training, each of the children was given their own hook and a separate short tube, which were replaced by a single hook and one short tube during the actual test.

\section{Procedure}

Data collection for all studies took place between October 2012 and September 2014. Instructions for all children were videotaped and played back using a laptop computer. In Kenya, all instructions were translated from English to the local language by native Kikuyu or Samburu speakers. Back translations were obtained in order to ensure correctness

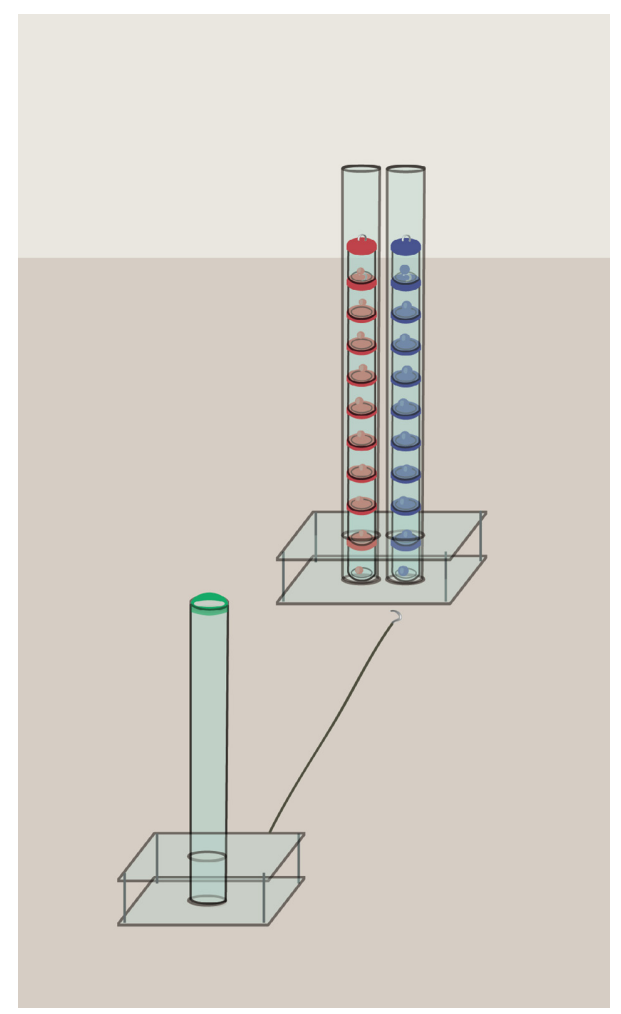

Figure 1. Experimental setup (Study 1). before recording the instructions. In Germany, instructions were written and recorded by a native German speaker. All studies took place in a separate room of the local school which the participants attended. Sessions were videotaped and took between 20 and $30 \mathrm{~min}$.

Children were randomly paired into same-age, same-sex dyads, and then went through the following three steps.

Video instructions. Each session started with a video introducing the participants to the game. The video showed the training setup with two children fishing several containers and placing them in their respective short tubes. At the end of the game, the containers were emptied by the experimenter and each child was given the rewards inside. A narrator explained the game in the local language and emphasized that the children would only be able to keep the rewards that they had placed inside the short tube. The child assigned to the blue side could keep the rewards inside the blue containers, and the child on the red side would be able to keep the rewards inside the red containers placed in the short tube.

Training. After watching the instruction video, children simultaneously played the first round of the game with the experimenter present. Once both children had filled their short tubes with eight containers each, the experimenter reminded them that the game was now over and emptied the fished containers. Each child was given the eight beads he or she had fished and asked to string them into a bracelet. The experimenter then refilled the containers and put them back into the long tubes. After telling the children that they could play another round, the experimenter left the room and waited outside until the short tubes had been filled again. As before, the fished containers were later emptied and each child got to keep the eight beads that he or she had fished. The complete training session lasted between 20 and $30 \mathrm{~min}$.

Test phase. While the children were stringing their beads, the experimenter removed the two hooks and both of the short tubes, one of which was later returned to the game. She then refilled the containers with beads, placed them back in the two long tubes, and placed a short tube at equidistance from the children's long tubes. After both children had finished stringing their beads, the experimenter then told them that they could now play again. When the children were standing next to their long tubes, the experimenter placed a single hook between the children, told them to start, and left the room. Once the children had fished a total 
of eight containers, the experimenter re-entered the room, emptied the containers, and asked the children to string their beads. If the children had agreed to take turns fishing, each of them would add a certain number of beads to their bracelets. If one child had monopolized the hook throughout the game, the other child would remain without additional beads. After again refilling the empty containers and long tubes, the children were informed that they could now play one last round of the game. The experimenter then again placed the hook between the two children, told them to start, and left the room. After the short tube had been filled, the fished containers were emptied once more. The children got to string their additional beads, and the experimenter then closed the bracelets for them, ending the game.

\section{Coding}

The number of rewards obtained by each child was recorded at the end of each test round. Inequality was measured as the absolute difference between the numbers of rewards each child had obtained. Since there was a total of eight rewards available per trial, inequality ranged from 0 to 8 within trials, and from 0 to 16 across trials.

Behaviors were later coded from video material using Interact software. Initial actions (ways of first obtaining the hook at the beginning of each trial) were coded as seizes, grabs, or takes. If there was a tug-of-war over the hook, with both children struggling to keep it, the action was coded as seizes, indicating that the user had obtained possession of the hook by force. If both children reached for the hook but the faster child got to use it without physical interference, the action was coded as grabs, with speed deciding the first use of the hook. And if only one child reached for the hook and got to use it without her partner's interference, the action was coded as takes, suggesting that there was an agreement over the use of the hook. Turn-taking within trials was coded either with hands over (user gives up hook without being physically forced) or loses (nonuser forces hook out of user's hand). In addition, we coded for protest (both verbal and nonverbal) at the beginning of the second trial. Reliability was obtained by having an independent observer code $20 \%$ of the video material. Intercoder reliability across categories was very good (Kendall's tau-b coefficient $=.899, p<.001$ ). Due to corrupted video files, we were not able to obtain behavioral measures for three German dyads (two 7-year-old and four 10-year-old boys), who were thus excluded from all analyses involving behavioral data.

\section{Results}

Our main questions in Study 1 were whether culture, age, or their interaction would have an effect on children's turn-taking behavior and an equal distribution of resources. In order to address these questions, we analyzed the data using generalized linear models (GLMs) with Poisson error structure and log link function (turn-taking) or binomial error structure and logit link function (resource distribution). Gender was included as a control variable in all models. To account for multiple testing, overall significance of all test variables was established by comparing the full model to that of a reduced model only comprising gender. All models were fitted in R (version 3.0.2; R Core Team 2013) using the function glm. Assumptions were validated and met in each case (see Supporting Information for details).

\section{Turn-Taking}

Our main question was whether turn-taking as a way of sharing access to resources within trials was common across cultures, and whether it had been initiated by agreement or force. The number of dyads who took turns within trials differed significantly between cultures (Pearson's chi-square test: $\left.\chi^{2}=60.95, d f=2, p<.001\right)$. Subsequent pairwise comparisons revealed that German children took turns significantly more often than Samburu or Kikuyu (Fisher's exact test: $p<.001$ in each case), whereas the number of turn-taking dyads did not differ significantly between the two Kenyan communities (Fisher's exact test: $p=.093$ ).

Due to the vast differences in the total number of turns and the low frequency of forced turns within trials (Germans: 0\%, Kikuyu: 6\%, Samburu: $21 \%$ of all turns) we were not able to compare the proportion of forced versus agreed turns between the three cultures. Subsequent analyses therefore focused on agreed turns. In order to investigate the effects of culture, age, or their interaction on the frequency of agreed turns in each trial, we analyzed the data using GLMs with Poisson error structure. Overall the full models for Trials 1 and 2 were highly significant as compared to the null models containing only gender (likelihood ratio tests: Trial 1: $\chi^{2}=359.28, d f=5, p<.001$; Trial 2: $\chi^{2}=286.93$, $d f=5, p<.001)$. We found an interaction between culture and age, which had an effect on the 
frequency of agreed turns in both trials (likelihood ratio tests comparing full and reduced models: Trial 1: $\chi^{2}=5.94, d f=2, p=.051$; Trial 2: $\chi^{2}=7.58$, $d f=2, p=.023)$. The effect of age on the frequency of agreed turns was significantly different between Germans and Kikuyu (Trial 1: $z=-2.39, p=.017$; Trial 2: $z=-2.16, p=.031$ ), with German children taking more agreed turns as they got older. However, the effect of age on the number of agreed turns was not significantly different between Germans and Samburu (Trial 1: $z=-0.13, p=.896$; Trial 2: $z=0.07, p=.942)$ or between Kikuyu and Samburu (Trial 1: $z=1.65, p=.099$; Trial 2: $z=1.63, p=.103$; see Figures S1 and S2).

Having looked at turn-taking within trials, we also wanted to know what happened between trials. Would children agree on using the hook before the second trial? If one of the children waited for her partner to take the hook, we assumed that there was an implicit agreement about whose turn it was. If both children reached for the hook and the faster or stronger child ended up using it, we did not assume any prior plans. Across cultures, children seemed to agree a lot on who would get to use the hook, and only very few children gained access by force (see Table 1 for an overview of initial actions in Trial 2). Overall we found no significant correlations between culture and the type of initial action at the beginning of the second trial (Pearson's chisquare: $\chi^{2}=7.33, d f=6, p=.291$ ).

While the initial actions mattered less if children were taking turns within trials, it was crucial to determine how children had come to use the hook when they were taking turns between trials only. If both children reached for the hook and the other one happened to be faster, equal distributions across trials might simply be due to chance. However, if the children who had monopolized the resources in Trial 1 did not reach for the hook, we assumed that they were prepared to remain without rewards in Trial 2. Most of the cases in

Table 1

Initial Actions in Trial 2

\begin{tabular}{lccr}
\hline & \multicolumn{3}{c}{ Initial actions (\%) } \\
\cline { 2 - 4 } & Takes & Grabs & Seizes \\
\hline German & 75.0 & 17.9 & 7.1 \\
Samburu & 58.0 & 22.0 & 20.0 \\
Kikuyu & 67.8 & 25.4 & 6.8 \\
\hline
\end{tabular}

Note. Takes $=$ hook obtained without partner's interference; grabs = hook obtained through speed; seizes = hook obtained by force. which children took turns between trials only showed the second pattern; that is, the child who had previously fished all rewards did not reach for the hook at the beginning of the second trial. In Germany that was true for 4 of the 7 cases, Kikuyu children let their partners take the hook in 13 of the 19 cases, and in Samburu, 14 of the 17 dyads showed this behavior (see Table 2 for an overview of turn-taking behaviors).

\section{Resource Distribution}

Our next question was how resources would be distributed both within and across trials. Since most dyads had either shared equally or not at all within the first trial, the response we used for our model was whether the distribution was unequal (difference score $=8$ ) or not (difference score $=0$; see also Tables S1 and S2). Overall the full model was highly significant as compared to the null model $\left(\chi^{2}=100.24, d f=5, p<.001\right)$. There was no significant interaction between culture and age $\left(\chi^{2}=4.16\right.$, $d f=2, p=.125)$, and both culture and age had an effect on the inequality of distribution within the first trial (likelihood ratio test for culture: $\chi^{2}=93.60, d f=2, p<.001$; likelihood ratio test for age: $\left.\chi^{2}=4.99, d f=1, p=.025\right)$. Samburu and Kikuyu children distributed resources significantly more often in an unequal way than did their German peers (Germans vs. Samburu: $z=6.00$, $p<.001$; Germans vs. Kikuyu: $z=6.52, p<.001$ ). In all cultures, inequality within Trial 1 decreased with age.

The initial pattern continued across trials, with children sharing either equally or not at all. Therefore, the response we used for the model was again whether or not the distribution was unequal. Again, the full model was highly significant as compared to the null model $\left(\chi^{2}=47.24, d f=5\right.$, $p<.001)$, and we found no interaction between culture and age $\left(\chi^{2}=3.13, d f=2, p=.209\right)$. Across trials, culture continued to have a clear effect on the inequality of distribution $\left(\chi^{2}=44.09, \quad d f=2\right.$, $p<.001)$. As in Trial 1, children from the two Kenyan populations ended up with an unequal distribution of resources more often than their German peers (see Figure 2).

The age effect also disappeared when looking across trials $\left(\chi^{2}=0.001, d f=1, p=.974\right)$.

\section{Occurrence and Influence of Protest in Trial 2}

Following the results of our previous analyses, we were interested to find out whether children 
Table 2

Turn-Taking Patterns Across Cultures

\begin{tabular}{|c|c|c|c|c|c|}
\hline & $\begin{array}{l}\text { Dyads with } \\
\text { voluntary turns } \\
\text { within trial }\end{array}$ & $\begin{array}{l}\text { Dyads with voluntary } \\
\text { turns between } \\
\text { trials only }\end{array}$ & $\begin{array}{l}\text { Dyads with involuntary } \\
\text { turns between trials only }\end{array}$ & $\begin{array}{l}\text { Dyads without } \\
\text { turn-taking }\end{array}$ & Total dyads \\
\hline German & 46 & 4 & 3 & 3 & 56 \\
\hline Samburu & 12 & 14 & 3 & 21 & 50 \\
\hline Kikuyu & 9 & 13 & 6 & 31 & 59 \\
\hline
\end{tabular}

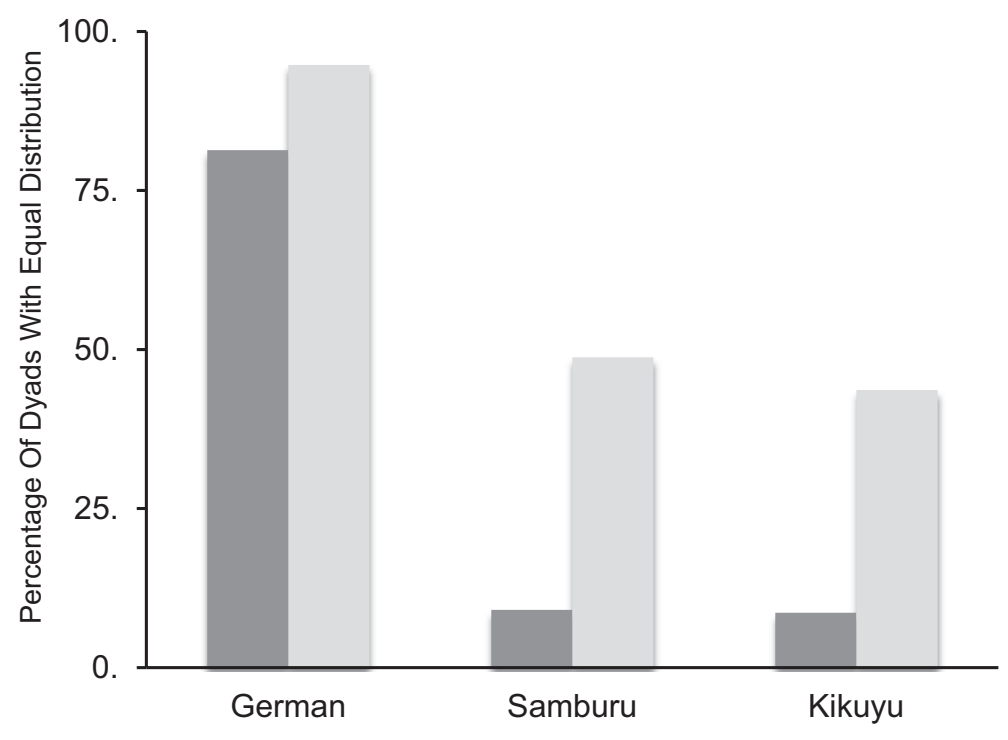

- TRIAL 1

Across Trials

Figure 2. Percentage of dyads with equal distribution of resources.

who had obtained fewer rewards in Trial 1 would protest at the beginning of the second trial if the partner continued using the hook. Specifically, we wanted to see whether protest would lead to an increase in rewards obtained in the second trial. We thus used a logistic GLM analyzing the effects of culture, age, the interaction of culture and age, and protest on the amount of rewards obtained in Trial 2. Overall the full model was significant as compared to the null model (likelihood ratio test: $\left.\chi^{2}=15.46, d f=6, p=.017\right)$. A likelihood ratio test comparing the full and the reduced model revealed no significant interactions $\left(\chi^{2}=0.05, d f=2\right.$, $p=.975)$. The reduced model revealed an effect of protest $\left(\chi^{2}=11.03, d f=1, p<.001\right)$, indicating that the number of cases in which protest was followed by an increase in resources was significantly lower than the number of cases in which protest was ignored (see Figure 3). Age did not seem to have any effect (age: $\chi^{2}=0.01, d f=1, p=.931$ ), and there were no significant differences between cultures $\left(\chi^{2}=4.87, d f=2, p=.088\right)$.

\section{Discussion}

The vast majority of German children solved the task by taking turns and carefully distributing resources between the two partners, which resulted in a high level of equality both within and across trials. Samburu and Kikuyu children, on the other hand, seemed to be much less concerned about (at least temporary) inequalities. When aiming for an equal distribution at all, they mostly did so by taking turns between trials rather than within. And even if the dominant child continued to monopolize the resources, there was very little protest-and most of it remained unheard.

\section{Study 2}

Were the rewards perhaps too attractive for the two Kenyan groups to interrupt the game once they had started fishing? Or did the Kenyan children simply think that distributing resources on a 


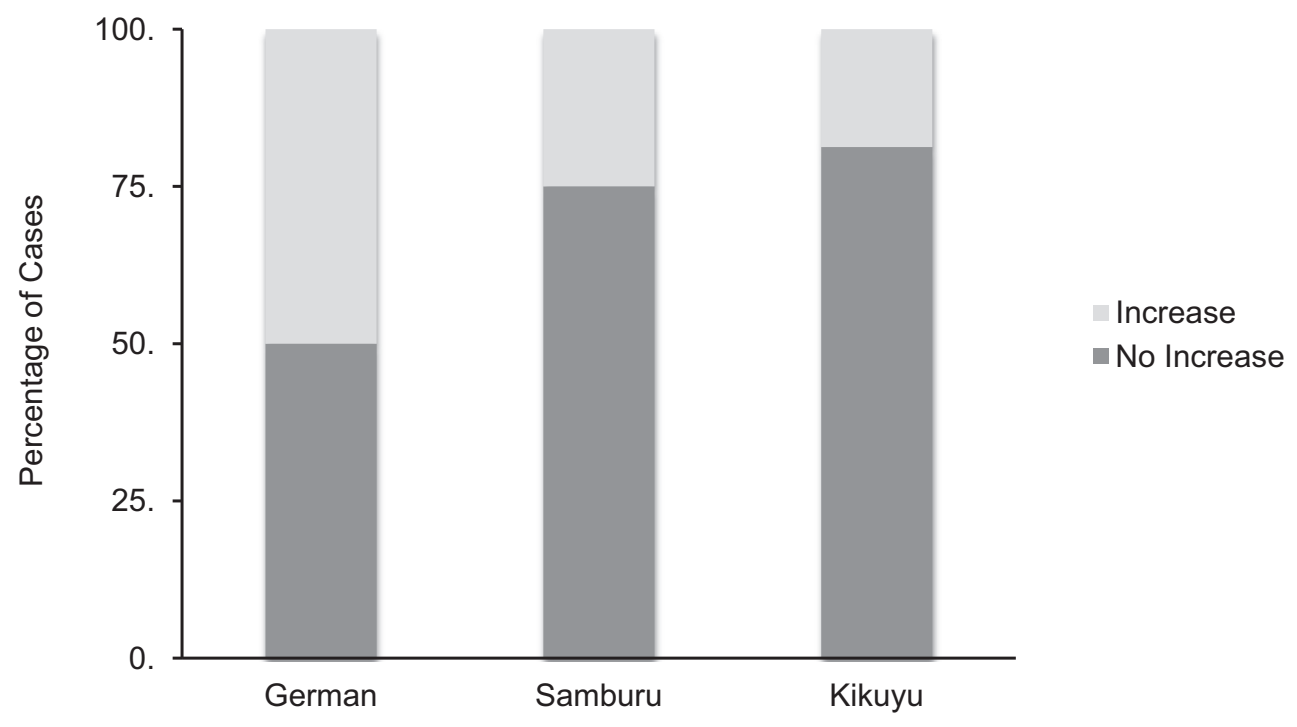

Figure 3. Percentage of cases with or without increase in resources following protest.

first-come, first-served basis was the right thing to do? And did the German children just take turns in order to avoid complaints from their partners or would they also prefer that strategy if they were not involved in the game? In order to address these questions, we added a third-party context to see whether or not children would think that taking turns was the right thing to do if they were not directly concerned.

\section{Method}

\section{Participants}

A total of 24 Kikuyu, 37 Samburu, and 42 German children between the ages of 7 and 11 who had participated in Study 1 in the previous year were tested in Study 2, Kikuyu: 7 girls $\left(M_{\text {age }}=8.0\right), 17$ boys $\left(M_{\text {age }}=9.5\right)$; Samburu: 20 girls $\left(M_{\text {age }}=9.5\right), 17$ boys $\left(M_{\text {age }}=8.5\right)$; Germans: 17 girls $\left(M_{\text {age }}=8.6\right), 25$ boys $\left(M_{\text {age }}=9.2\right)$. Another three Kikuyu and six Samburu children (Kikuyu: one 7-year-old boy, two 10-year-old girls; Samburu: two 8-year-old girls, three 10-year-old boys, and one 11-year-old boy) were tested but excluded because they had answered the recapitulation questions incorrectly.

\section{Materials and Procedure}

Children were shown various pictures and videos on a laptop and asked to answer questions either verbally or by pointing to the correct solution on the screen (see Supporting Information for details). Having correctly answered all warm-up questions, children then proceeded to the actual test. In the test video, children were reminded of the fishing game that they had played some time ago. Subsequently, they were introduced to a fictional boy called Anthony (or a girl called Anne) who would be playing the game with a partner. After watching Anthony and his partner play one round of the fishing game, children were asked to count the number of containers each child had fished and the amount of rewards they would get. Anthony had taken turns playing with the other child, so each of the two partners received four rewards. Next, a boy called David (or a girl called Diana) was introduced, and children again watched him play one round of the game, followed by counting containers and rewards. David had not let the other child fish, so he received eight rewards and his partner none. The order of the two game versions was counterbalanced. Male participants saw David and Anthony playing; female participants watched Diana and Anne. After a short summary of what they had just seen, children were shown pictures of the two main actors and asked to recapitulate: Which child let the other one play, too? And which child got more rewards? Having passed the memory test, children were then asked to point to the actor who had played the game the way it should be played. Children who had failed the memory test also proceeded to the last question but were not included in the analysis. After answering the last question, children received a small reward and the test session ended. 


\section{Coding}

All answers were recorded live by the experimenter. Reliability was obtained by having an independent observer code $20 \%$ of the relevant videotaped material of the sessions (recapitulation and test questions). Intercoder reliability was very good (Kendall's tau-b coefficient $=1.000, p<.001$ ).

\section{Results}

About $75 \%$ of our Kenyan children thought that the actors who had not taken turns had played the game the way it should be played. German children unanimously said that taking turns was the right thing to do (see Figure 4).

In order to investigate the effects of culture, age, and their interaction on the children's reply, we analyzed the data using a GLM with binomial error structure (see Study 1 for details). As a response for our model we used whether children had answered "take turns" or not. Overall the full model was highly significant as compared to the null model containing only gender (likelihood ratio test: $\left.\chi^{2}=82.15, d f=5, p<.001\right)$. There was no significant interaction between culture and age $\left(\chi^{2}=0.15\right.$, $d f=2, p=.926)$, and both culture and age had an effect on the children's reply (likelihood ratio test for culture: $\chi^{2}=79.50, d f=2, p<.001$; likelihood ratio test for age: $\chi^{2}=5.28, d f=1, p=.022$ ).

\section{Discussion}

Consistent with our previous findings, most children from our two Kenyan groups thought that peers who had monopolized the resources had played the game the way it should be played, while German children insisted that taking turns was the right thing to do.

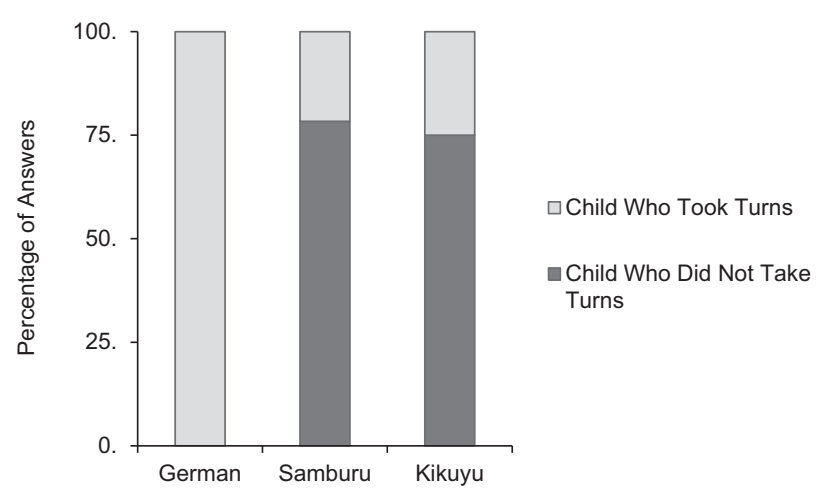

Figure 4. Answers chosen in reply to test question.

\section{Study 3}

Unlike their German peers who had solved all previous tasks in a very uniform way, there had been quite a bit of variation among the Kenyan dyads. In order to see whether the Kenyan children would converge to a more uniform strategy if the benefits of taking turns were higher, we introduced two new conditions in which the players would be observed by a peer or have the chance to be chosen as partners for another round with even higher payoffs.

\section{Method}

\section{Participants}

A total of 132 Kenyan children (80 Kikuyu and 52 Samburu) between the ages of 5 and 10 years who had previously participated in Study 1 were randomly chosen for Study 3. Children were recombined into new same-age, same-sex dyads and assigned to one of the three conditions.

In the control condition, we tested 26 Kikuyu and 16 Samburu children, Kikuyu: 10 girls $\left(M_{\text {age }}=7.6\right), 16$ boys $\left(M_{\text {age }}=7.1\right)$; Samburu: 8 girls $\left(M_{\text {age }}=7.5\right), 8$ boys $\left(M_{\text {age }}=7.5\right)$. Another 26 Kikuyu and 16 Samburu children were tested in the observer condition, Kikuyu: 10 girls $\left(M_{\text {age }}=7.6\right), 16$ boys $\left(M_{\text {age }}=7.1\right)$; Samburu: $\left(8\right.$ girls $\left(M_{\text {age }}=7.5\right), 8$ boys $\left(M_{\text {age }}=8.5\right)$. In the knowledge condition, we tested 28 Kikuyu and 22 Samburu children, Kikuyu: 12 girls $\left(M_{\text {age }}=6.7\right)$, 16 boys $\left(M_{\text {age }}=8.5\right)$; Samburu: 10 girls $\left(M_{\text {age }}=8.0\right), 12$ boys $\left(M_{\text {age }}=7.5\right)$. Another two 5-year-old Kikuyu and two 8-year-old Samburu boys were tested but excluded because the Kikuyu observer had given instructions, and the Samburu children had not followed the game rules. In addition, another 13 children aged between 11 and 15 years took part as observers in the observer and knowledge conditions, Kikuyu: $N=7,2$ girls $\left(M_{\text {age }}=13.0\right), 5$ boys $\left(M_{\text {age }}=13.0\right)$; Samburu: $N=6,3$ girls $\left(M_{\text {age }}=13.0\right), 3$ boys $\left(M_{\text {age }}=13.0\right)$.

\section{Materials}

Materials consisted of the basic setup described in Study 1, and an additional setup including two long tubes, which were filled with 10 green or yellow containers each. As opposed to the blue and red containers (which were again filled with one small bead), the green and yellow containers were filled with two large beads each. All 
rewards were clearly visible from the outside. On the yellow side, there was a clear box containing a single hook. Another two long, but opaque boxes (only one containing a hook) were placed next to the basic setup at the beginning of the game.

\section{Procedure}

Again all sessions started with a short video. Since all participants had played the fishing game before, they were familiar with the basic procedure. The instruction video therefore only gave a brief reintroduction to the game and then continued depending on the condition. There were three conditions: In the control condition, the narrator briefly mentioned that there was another game with even more and bigger rewards, which the children could perhaps play later. In the observer condition, the narrator added that there would be another child watching; and in the knowledge condition, he also mentioned that the observer would later choose one of the two players to be his partner in the other game. In the observer and knowledge conditions, an older child was seated next to the second setup, on the side that did not have a hook (see Figure S3). Prior to the test, the observer had been instructed to remain silent throughout the game. In order to predetermine which child would get the hook in the first round, it was placed in one of the two opaque boxes next to the first game setup. The children did not know that there was only one hook available and only discovered who had it after the start of the game. After watching the instruction video, the experimenter told the children to start playing and left the room. When the children had filled the first short tube, the experimenter entered the room, emptied the fished containers, and distributed the beads accordingly. In the control and observer conditions, she then thanked the children for playing and ended the test. In the knowledge condition, the experimenter asked the observer to pick a partner for the high-reward game. The child who had not been selected was given a small reward (in addition to any beads she might have fished) and left the room. The other two were then told to start playing the high-reward game. As stated earlier, the experimenter left the room while the children were fishing and only re-entered after the short tube had been filled with a total of eight containers. She then emptied the fished containers, distributed the beads, and ended the test.

\section{Coding}

The number of rewards obtained by each child was recorded life at the end of each round. In the knowledge condition, the observer's choice was recorded as well. Inequality measures were again obtained by calculating the absolute difference between the numbers of rewards each child had fished. Reliability was obtained by having an independent observer code $20 \%$ of the video material. Intercoder reliability was very good across categories (Kendall's tau-b coefficient $=.899, p<.001$ ).

\section{Results}

In order to investigate the effects of culture, age, and condition on the probability of having an unequal distribution, we analyzed the data using a GLM with binomial error structure (see Study 1 for details). Overall the full model was not significant as compared to the null model containing only gender (likelihood ratio test: $\chi^{2}=5.58, d f=5, p=.349$ ), indicating that culture, age, and condition had no effect on the inequality of distribution. Figure 5 presents the percentage of equal and unequal distributions obtained in each condition. To complete the picture, we analyzed whether the observer in the knowledge condition would choose the child who had previously obtained less rewards or the one who had obtained more. Neither Kikuyu nor Samburu observers showed a clear preference for either one of the two options (binomial test: Kikuyu: $p=.791$; Samburu: $p=.549$; see Figure S4).

\section{Discussion}

Children in both cultures continued using the mix of strategies we had seen in the original study, irrespective of being observed or having the chance to play in a more lucrative game later. The observer's subsequent choice did not seem to follow a particular pattern either, suggesting that children did not apply a general distribution strategy to the game.

\section{General Discussion}

Turn-taking could easily be viewed as a natural solution to a problem of individuals with equal power facing a resource that can be accessed by only one of them at a time. Children from various cultures have been shown to use turn-taking strategies to solve such problems from early on (Hay \& 


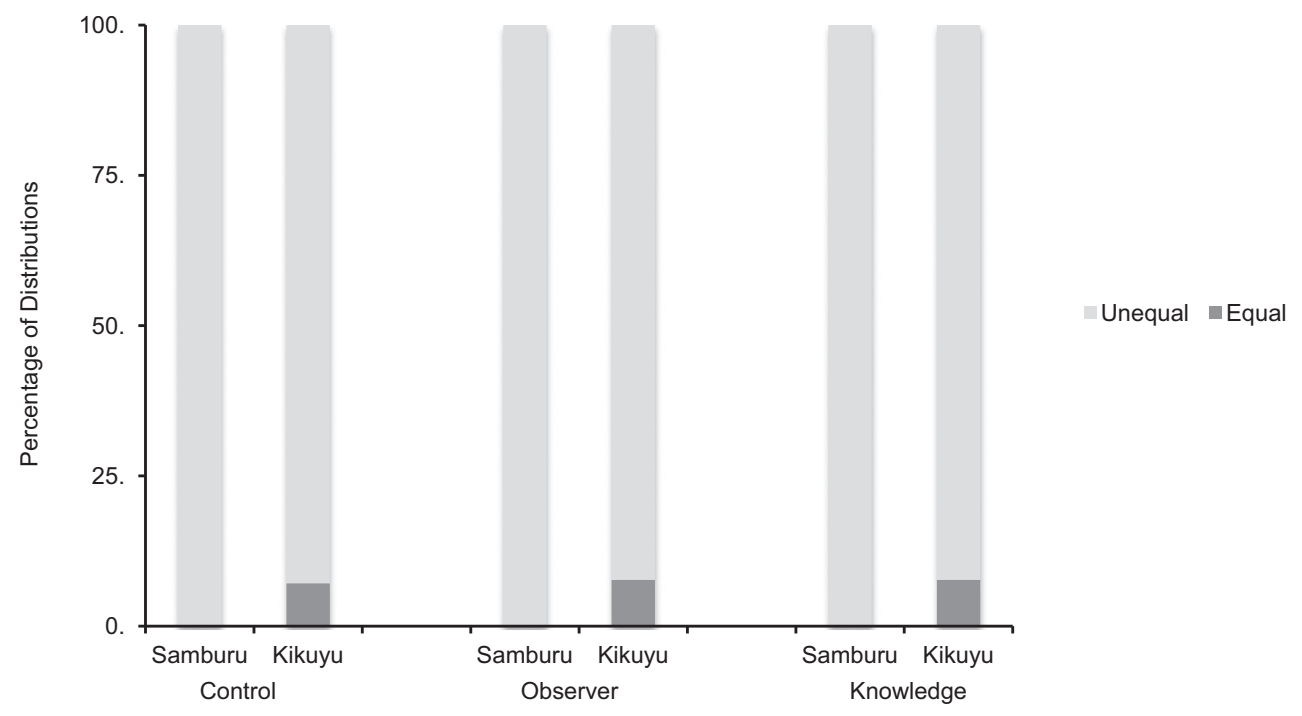

Figure 5. Percentage of equal versus unequal distributions for each condition.

Ross, 1982; Madsen, 1971; Putallaz \& Sheppard, 1990; Shapira, 1976; Sparkes, 1991). The results of the current cross-cultural studies may be interpreted as broadly consistent with this general idea in the sense that there were some peer pairs in all cultures who took turns in one way or another.

However, the overwhelming finding of the current studies is cross-cultural differences. In the vast majority of cases, the German children took turns accessing the resource, one by one, within each of the two trials. In contrast, this happened very infrequently with children from the two Kenyan populations-irrespective of their particular cultural background. Did the Kenyan children perhaps choose not to take turns because it was a new strategy that they had not been shown before? Kenyan teachers often require children to memorize and repeat what they have heard and rarely encourage innovation (Ngware, Oketch, \& Mutisya, 2014). However, if children thought that resources should be shared equally without breaking the original pattern, they still had a chance to take turns between trials - which only half of them did. One other explanation could have been that the Kenyan children thought that taking turns was the right thing to do, but in this novel situation with fairly valuable prizes, this judgment was overcome by selfish interests. But after having observed other children in the same task, most of our Kenyan participants said that the child monopolizing the resources, not the one taking turns, had played the game the way it should be played. Again, Kikuyu and Samburu children responded in a very similar way-and very differently from their German peers. And when we tried to make it even more rewarding for Kenyan children to take turns in the third study-if they assumed that an observer would prefer a cooperative partner in the futuremost of them still did not do so. It therefore seems unlikely that the Kenyan children were somehow more motivated for the prizes.

From the beginning most German children seemed to think that the point of the game was to agree on a strategy and share equally right away, whereas the majority of Samburu and Kikuyu children started out with a first-come, first-served approach. Nevertheless, it should be noted that close to half of the Kenyan children took turns across trials; that is, one of them monopolized the resources in Trial 1 and the other did so in Trial 2. This pattern was not set up by explicit agreement in any way that we could tell, but it was not the case that the second child had to fight to get a turn in the second trial. In the vast majority of cases, the child who had monopolized the resources in Trial 1 simply allowed the disadvantaged child to monopolize them in Trial 2. This suggests that the first child in some sense felt less entitled to the resources in the second trial after having monopolized them in Trial 1 (or felt that the other child, having been disadvantaged before, would be insistent if he or she did not now get a turn). Perhaps the German children simply anticipated this situation and began taking turns immediately within the first trial. Needless to say, the kind of constant reminders from parents to take turns with toys and other resources, characteristic of parents in Western societies, might have helped 
the German children to make this anticipation. When asked about their teaching strategies, the vast majority of our German parents stated that they would not only tell their children to take turns, but also try to make them understand why it is important to do so-which might help the children to internalize it as their own rule and apply it widely (Baumrind, 1971). Kenyan parents, on the other hand, tend to rely more on external mechanisms for regulating their children's behavior. Less than half of the Samburu parents we interviewed said they would teach their children to take turns, and the majority would solve conflicts between children by removing the toy. Kikuyu parents did tell their children to take turns, but then mostly relied on external measures to enforce it (see Supporting Information for details). Nevertheless, both Samburu and Kikuyu thought that it was important to share and take turns - and they also do so on a regular basis. Children often play hopscotch, rope jumping, or pebble games that involve turn-taking, and adults take turns using utensils or tools. Other items such as tobacco, tea leaves, or charcoal are widely shared among adults as well, but not so much in a context of direct exchange or equal distribution. Often, family members or neighbors will simply ask for things that they are lacking and receive whatever the owner can spare. In addition, families are expected to supply food for the community on certain occasions such as initiation ceremonies or weddings, but again, the focus is not on an immediate exchange or equal division of resources. Children are usually present in most of these situations, but they rarely get to distribute resources themselves. But in a place where everyone knows everyone and local institutions will ensure that resources are commonly shared at some point, avoiding or immediately removing inequalities - and teaching their children to do the same-also seems less important. Long-term balancing might simply be a better option in places where people know each other and interact repeatedly in specific contexts, while large-scale societies might have developed norms for immediately resolving resource problems in order to sustain cooperation among strangers (Chudek \& Henrich, 2011).

Taking turns to access limited resources might thus be a generic approach in some cultures, but applied less widely and across different time scales in others. As Michael Cole put it, "[C]ultural differences in cognition reside more in the situation to which particular cognitive processes are applied than in the existence of a process in one cultural group and its absence in another" (Cole, Gay, Glick, \& Sharp, 1971, p. 233).

The current study is a first step in determining how children in different cultural settings share resources that can be accessed by only one individual at a time, but there are still a number of important questions to be answered. For example, it would be interesting to see whether children generalize their behavior across situations or whether there might be context-specific differences. In addition, it would be important to know the degree to which children were simply following an adult rule versus making a spontaneous judgment about the appropriate distribution.

Overall the current results have demonstrated rather strong differences in the way in which children from different cultural backgrounds approached a limited resource problem. These differences are presumably due to variations in the children's sociocultural environments, though the precise mechanisms involved are still to be determined.

\section{References}

Baumrind, D. (1971). Current patterns of parental authority. Developmental Psychology, 4, 1. doi:10.1037/ h0030372

Benenson, J. F., Pascoe, J., \& Radmore, N. (2007). Children's altruistic behavior in the dictator game. Evolution and Human Behavior, 28, 168-175. doi:10.1016/j.evolhumbehav.2006.10.003

Blake, P. R., \& McAuliffe, K. (2011). "I had so much it didn't seem fair": Eight-year-olds reject two forms of inequity. Cognition, 120, 215-224. doi:10.1016/j.cognition.2011.04.006

Chudek, M., \& Henrich, J. (2011). Culture-gene coevolution, norm-psychology and the emergence of human prosociality. Trends in Cognitive Sciences, 15, 218-226. doi:10.1016/j.tics.2011.03.003

Cole, M., Gay, J., Glick, J., \& Sharp, D. W. (1971). The cultural context of learning and thinking. New York, NY: Basic Books.

Fehr, E., Bernhard, H., \& Rockenbach, B. (2008). Egalitarianism in young children. Nature, 454, 1079-1084. doi:10.1038/nature07155

Green, V. A., \& Rechis, R. (2006). Children's cooperative and competitive interactions in limited resource situations: A literature review. Applied Developmental Psychology, 27, 42-59. doi:10.1016/j.appdev.2005.12.002

Hay, D. F., \& Ross, H. (1982). The social nature of early conflict. Child Development, 53, 105-113. doi:10.2307/ 1129642

Henrich, J., Ensminger, J., McElreath, R., Barr, A., Barrett, C., Bolyanatz, A., .. L Lesorogol, C. (2010). Markets, 
religion, community size, and the evolution of fairness and punishment. Science, 327, 1480-1484. doi:10.1126/ science. 1182238

House, B., Silk, J. B., Henrich, J., Barrett, C., Scelza, B., Boyette, A., . . L Laurence, S. (2013). The ontogeny of prosocial behavior across diverse societies. Proceedings of the National Academy of Sciences of the United States of America, 110, 14586-14591. doi:10.1073/pnas.1221217110

Madsen, M. C. (1971). Developmental and cross-cultural differences in the cooperative and competitive behavior of young children. Cross-Cultural Psychology, 2, 365-371. doi: $10.1177 / 002202217100200406$

Madsen, M. C., \& Lancy, D. F. (1981). Cooperative and competitive behavior. Experiments related to ethnic identity and urbanization in Papua New Guinea. Journal of Cross-Cultural Psychology, 12, 389-408. doi:10.1177/0022022181124001

Madsen, M. C., \& Yi, S. (1975). Cooperation and competition of urban and rural children in the Republic of South Korea. International Journal of Psychology, 10, 269274. doi:10.1080/00207597508247338

Ngware, M. W., Oketch, M., \& Mutisya, M. (2014). Does teaching style explain differences in learner achievement in low and high performing schools in Kenya? International Journal of Educational Development, 36, 3-12. doi:10.1016/j.ijedudev.2014.01.004

Putallaz, M., \& Sheppard, B. H. (1990). Social status and children's orientations to limited resources. Child Development, 61, 2022-2027. doi:10.1111/j.1467-8624.1990. tb03583.x

R Core Team. (2013). R: A language and environment for statistical computing. Vienna, Austria: R Foundation for Statistical Computing. Retrieved from http://www. R-project.org/

Shapira, A. (1976). Developmental differences in competitive behavior of kibbutz and city children in Israel. Journal of Social Psychology, 3, 353-359. doi:10.1080/ 00224545.1976.9923361
Shaw, A., \& Olson, K. R. (2012). Children discard a resource to avoid inequality. Journal of Experimental Psychology: General, 141, 382-395. doi:10.1037/ a0025907

Sparkes, K. (1991). Cooperative and competitive behavior in dyadic game-playing: A comparison of Anglo-American and Chinese children. Early Child Development and Care, 68, 37-47. doi:10.1080/0300443910680105

\section{Supporting Information}

Additional supporting information may be found in the online version of this article at the publisher's website:

Figure S1. Number of Agreed Turns in Trial 1

Figure S2. Number of Agreed Turns in Trial 2

Figure S3. Experimental Setup for Study 3

Figure S4. Percentage of Observers Choosing Children With Less, Equal, or More Resources in Round 1

Table S1. Number of Dyads With Difference Scores of 8 (Complete Inequality), 0 (Complete Equality), or Any Other Difference Score in Trial 1

Table S2. Number of Dyads With Difference Scores of 16 (Complete Inequality), 0 (Complete Equality), or Any Other Difference Score Across Trials

Table S3. Neighbors: Parents' Answers and Number of Times They Were Given

Table S4. Socialization: Parents' Answers (Summarized Into Categories) and Number of Times They Were Given

Appendix S1. Ethnographic Background 